Research Paper:

\title{
The Relationship Between Spiritual Health and General Self-Efficacy in the Iranian Elderly
}

\author{
Maedeh Chabok ${ }^{1}$, Zahra Kashaninia ${ }^{2 *}$, Hamid Haghani ${ }^{3}$
}

1. Department of Department of Geriatric Nursing, School of Nursing and Midwifery, Iran University of Medical Sciences, Tehran, Iran. 2. Department of Psychiatric Nursing and Rehabilitation, School of Nursing and Midwifery, Iran University of Medical Sciences, Tehran, Iran

3. Department of Biostatistics, School of Health Management and Medical Information, Iran University of Medical Sciences, Tehran, Iran.

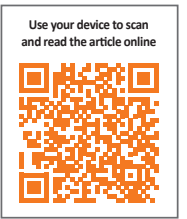

Citation: Chabok, M., Kashaninia, Z. \& Haghani, H., 2017. The Relationship Between Spiritual Health and General Self-Efficacy in the Iranian Elderly. Journal of Client-Centered Nursing Care, 3(2), pp. 125-132. https://doi.org/10.32598/jccnc.3.2.125

https://doi.org/10.32598/jccnc.3.2.125

Article info:

Received: 08 Sep. 2016

Accepted: 10 Jan. 2017

Keywords:

Elderly, Spirituality,

Religiosity, Self-efficacy

\section{A B S T RA C T}

Background: Elderliness is a sensitive period of life; so, it is necessary to pay special attention to various aspects of the health care for the elderly, including their spiritual well-being in the society. Spirituality and spiritual beliefs are closely associated with psychological aspects of a human mind, and they aim at balancing one's life. Self-efficacy is one of the psychological aspects, which play an important role in maintaining the mental and physical health. This study was conducted to determine the relationship between spiritual wellbeing and general self-efficacy in the elderly population of Tehran.

Methods: This descriptive correlational study was conducted on 822 elderly people who regularly visited some of the parks of Tehran, Iran, in 2015. Samples were chosen by the multistage method. The relevant data were collected through demographic information in addition to tests and questionnaires including Abbreviated Mental Test Score (AMTS) for determining cognitive impairment and General Self-Efficacy (GSE-10) y and Spiritual Well-Being Scale (SWBS). The data were analyzed using Pearson correlation and t-tests by SPSS Version: 20.0.

Results: The results of the current study showed that general self-efficacy is related to religious, existential, and spiritual health. The findings also indicated that among the demographic variables, spiritual health is mostly related to marital status and the ability to perform Activities of Daily Living (ADL) in addition to residence and income.

Conclusion: Since aging is an important challenge in the health system, promoting spiritual health in the elderly population can result in these individuals' high self-efficacy, ultimately leading to a higher physical and mental health status.

\section{* Corresponding Author:}




\section{Background}

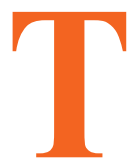

he World Health Organization defines the individuals over the age of sixty as elderly (World Health Organization 2013). Improving life conditions and health care facilities, and increasing life time and expectancy have led to an aging phenomenon in communities. This event raises the need for attention to strategies for improving their health, hygiene, social, welfare, rehabilitation, and quality of life (Victor, Burholt \& Martin 2012). Health has four dimensions: physical, psychological, social, and spiritual amongst which spiritual health is the most recently recognized health dimension (Rahimi et al. 2013).

Spiritual health means having a state or a positive feeling in relationships with others and encompassing transcendental dimensions that give the person a sense of identity, integrity, satisfaction, beauty, love, respect, positive attitude, inner peace and harmony, purpose, and direction In life (Velasco-Gonzalez \& Rioux 2013). It has two distinct dimensions including religious and existential health, wherein religious health relates to one's understanding of spiritual well-being and his relationship with God and superior power and existential health refers to how a person adjusts himself to the community and surrounding environment, which includes the purpose of life, positive and negative experiences, and life satisfaction (Bai \& Dixon 2014). Promoting spiritual health may not cure an illness, but it can help a person to feel better, prevent some health problems, and affect treatment process (Bai \& Lazenby 2015).

Some studies have indicated that lack of spiritual health causes bad performance of biological, psychological, and social dimensions and inability to achieve the maximum capacity (Hosseini, Torkani \& Tavakol 2013). One of the psychological dimensions that play an important role in human mental and physical health is self-efficacy based beliefs. Self-efficacy is a belief that one has the ability to organize and carry out the necessary behaviors to achieve his or her goals (French et al. 2014). This belief may highly affect the person's motivation to perform activities and endure in dealing with problems. Self-efficacy also means believing in their abilities to overcome unique challenges, which leads to increased individual adaptation and appropriate responses to stressful situations (Adegbola 2011). Self-efficacy varies according to age, which increases throughout the childhood and early adulthood, reaches its highest in the middle age and decreases after 60 years old (Bekhet \& Zauszniewski 2012).
Several studies have shown the role of physical and mental health in promoting self-efficacy of individuals, but so far, there has not been a study to investigate the relationship between spiritual well-being and self-efficacy in the elderly population (Griffin 2012). In 2009, a study was conducted to understand the relationships between spirituality, health self-efficacy and health locus of control in the elderly of the Japanese population. The results of this study showed, there is a positive relationship between health self-efficacy and spirituality in relation to the purpose of life, faith, respect to others ( $\mathrm{P}$ $<0.001$ ) (Takeda et al. 2009).

In 2014, a study was conducted to investigate the relationship between academic self-efficacy and psychological well-being, family cohesion, and spiritual health among the students of Kharazmi University in Tehran Province, Tehran. This study revealed a positive and significant correlation between academic self-efficacy and spiritual well-being $(\mathrm{P}<0.001)$ (Asghari et al. 2014).

Several studies have anticipated that Iran will be facing the challenges of the aging population in the near future. It is estimated that the cost of care for elderly people with multiple physical and cognitive problems will rapidly increase in the next few decades. Therefore, it is important to understand the relationship between spiritual health and the components of physical and mental health (Lavretsky 2010). Among all the professional careers meant for elderly care, nursing can be considered as the most responsible one in the community. This is because during the hospitalization, between all other health care professionals, nurses spend most of their time with the elderly clients, and thus they are in a position to further assist them. Because of this understanding between the nursing staff and elderly, the spiritual health of the later plays a key role in further strengthening their relationship (Torki et al. 2011).

In order to evaluate the main research question, i.e. "Is there a relationship between spiritual well-being and general self-efficacy in elderly?", we measured the level of spiritual health in the elderly over 60 years old and their general self-efficacy, and then studied the relationship between these two variables. Finally, associations of these variables with demographic characteristics were measured.

\section{Materials \& Methods}

\section{Design and sample}

This is a descriptive correlational study conducted in 2015. Samples were chosen by multi-stage sampling. In 
the first stage, Tehran was classified into five regions; center, north, south, east, and west. Then one region from each of these five parts was selected by cluster sampling. Following this, by referring to the parks which were randomly selected from these areas, the sampling was done in the available method based on the inclusion criteria such as age more than 60 years old, having no disorder in communicating and receiving a score higher than six in the AMTS questionnaire. The sample size was initially estimated to be around 1000 participants. However, after the interview, 822 qualified volunteers who visited the parks of Tehran were included in the study. The cause of dropping sample size was the withdrawal of some elderly people from continuing to answer questions, marginalizing and not cooperating in answering some questions. This can be considered as one of the limitations of this study.

\section{Data collection}

Abbreviated Mental Test (AMT) was used to ensure there is no cognitive impairment among the samples. In 2014 the validity and reliability of this scale, with 10 questions was evaluated in elderly residents of Kahrizak Charity Foundation's facility in Iran (Cronbach's alpha coefficient $=0.76$ ). The maximum score in this test was 10 and the score of 6 and below meant the existence of a cognitive disorder (Bakhtiyari et al. 2014). Demographic characteristics questionnaire contained information such as age, gender, marital status, educational level, ability to perform ADL, employment status.

The Spiritual Well-Being Scale questionnaire (SWBS) was designed by Palautzine and Ellison in 1983, which consisted of 20 items in two components of spiritual (10 items) and existential (10 items) health. This questionnaire had six options for Likert scoring scale ranging from totally disagree to completely agree (1-6). Among these questions, the questions $1,2,5,6,9,12,13,16$ were scored negatively. The range of obtained scores varied from 10 to 120 and the higher score was considered as higher spiritual health. The low (40-20), medium (111-99), and high (120-100) spiritual health were also considered. The Cronbach's alpha coefficient in this study was evaluated at a rate of $83 \%$.

Schwartz \& Grosselm's General Self-Efficacy questionnaire (GSE-10) had 10 quadrants with a range of 1 to 4 , with a minimum and maximum score of 10 and 40 . The scores between 10 to 15,15 to 25 , and higher than 25 indicated the low, medium, and high level of self-efficacy, respectively. The Cronbach's alpha coefficient of this questionnaire was evaluated in this study, which was $93 \%$.
After taking permission from the University Research Ethics Committee at the Iran University of Medical Science and receiving ethical code, the researcher referred to the parks or gardens in the selected areas of Tehran in the morning and afternoon and received informed consent from the research participants. The scales were completed by interviewing method for about 20 minutes. This process lasted for about one year. In the end, data were analyzed by using Analysis of variance (ANOVA), Pearson correlation coefficient and linear regression by SPSS v. 20 (IBM, New York, United States).

\section{Results}

Demographic characteristics of samples are summarized in (Table 1). The majority of the elderlies were between 75 and 79 years old, and $61.3 \%$ of them were male. More than half of them (59.6\%) were married and had 0 to 3 children (50.6\%). The Spiritual health score was $73.72 \pm 8.01$ and average score of religious health and existential health was almost at the same level. The frequency distribution of spiritual health of the units showed that $66.2 \%$ of them had a high level of spiritual health and $33.8 \%$ had a moderate one (Table 3 ). ANOVA showed that spiritual health had a significant relationship with some demographic characteristics such as the area of residence, age, level of education, ability to perform ADL3, marital status, and status of residence, income ( $P$ $<0.001)$ and was highly related with marital status and ability to perform ADL (Table 2).

The self-efficacy score of the elderly was $24.71 \pm 5.68$ (Table 4). Among all demographics, self-efficacy is related to the area of residence, age, gender, education, marital status, ability to perform ADL and income status $(\mathrm{P}<0.001)$ and most related with ability to perform ADL, area of residence, and income status (Table 2). Results suggested that there was a significant correlation between general self-efficacy and religious, existential and spiritual health. The determination coefficients were calculated as $0.13,0.12$, and 0.19 respectively.

\section{Discussion}

The study results indicated that the most elders had high $(66.2 \%)$ and moderate (33.8\%) spiritual health scores. It should be noted that none of the units had low spiritual health and average spiritual health score was close to the median tool score. The research type and tools were similar to the ones employed by Jadidi et al. in his study, which investigated the relationship between spiritual health and the quality of life of elderly residents of the Kahrizak sanatorium in Tehran and showed that 
Table 1. The demographic characteristics of samples

\begin{tabular}{|c|c|c|c|}
\hline \multicolumn{2}{|c|}{ Demographic Variants } & \multirow{2}{*}{$\begin{array}{c}\text { Number } \\
170\end{array}$} & \multirow{2}{*}{$\begin{array}{r}\text { Percent } \\
20.7\end{array}$} \\
\hline \multirow{5}{*}{ Location area } & North & & \\
\hline & South & 151 & 18.4 \\
\hline & East & 181 & 22 \\
\hline & Center & 181 & 22 \\
\hline & West & 139 & 16.9 \\
\hline \multirow{5}{*}{ Age (years old) } & $60-65$ & 185 & 22.5 \\
\hline & $65-69$ & 156 & 19 \\
\hline & $70-74$ & 107 & 13 \\
\hline & $75-79$ & 325 & 39.5 \\
\hline & 80 and more & 49 & 6 \\
\hline \multirow{4}{*}{ Marital status } & Single & 32 & 4 \\
\hline & Married & 490 & 59.6 \\
\hline & Divorced & 81 & 9.9 \\
\hline & Dead wife & 218 & 26.5 \\
\hline \multirow{2}{*}{ Gender } & Female & 318 & 38.7 \\
\hline & Male & 504 & 61.3 \\
\hline \multirow{4}{*}{ Education level } & Illiterate & 218 & 26.5 \\
\hline & Reading and writing & 301 & 36.6 \\
\hline & Diploma & 158 & 19.2 \\
\hline & Above diploma & 145 & 17.6 \\
\hline \multirow{3}{*}{ Ability to perform ADL } & Yes & 579 & 70.4 \\
\hline & No & 16 & 1.9 \\
\hline & Somewhat & 227 & 27.6 \\
\hline \multirow{4}{*}{ Employment status } & Employed & 117 & 14.2 \\
\hline & Housewife & 135 & 16.4 \\
\hline & Retired & 551 & 67 \\
\hline & Out of work & 19 & 2.3 \\
\hline
\end{tabular}

Client-Centered Nursing Care

more than half of participants had high spiritual health $(52 \%)$. This is justified by the cultural and religious conditions of the Iranian people, who resort to religion in order to adapt to the crisis.
The results also showed that most of the units had a high level of self-efficacy (48.3\%) and moderate (45.7\%), and only $6 \%$ had a low level of general self-efficacy. The mean of self-efficacy score among the studied units was $24.71 \pm$ 5.68, which was close to the middle of the tool's score of 25 . 
Table 2. The numerical indexes of spiritual health and general self-efficacy in the studied units according to the demographic variable

\begin{tabular}{|c|c|c|c|c|c|}
\hline \multirow{2}{*}{\multicolumn{2}{|c|}{ Demographic Variants }} & \multicolumn{2}{|c|}{ Spiritual Health } & \multicolumn{2}{|c|}{ General Self-Efficacy } \\
\hline & & Mean (SD) & $\mathbf{P}$ & Mean (SD) & $\mathbf{P}$ \\
\hline \multirow{5}{*}{ Location area } & North & $76.04(7.13)$ & & $25.37(0.46)$ & \\
\hline & South & $71.82(8.32)$ & & $21.97(0.47)$ & \\
\hline & East & $73.18(7.56)$ & $P<0.001$ & $25.22(0.35)$ & $P<0.001$ \\
\hline & Center & $72.23(8.35)$ & & $24.17(0.45)$ & \\
\hline & West & $75.61(7.85)$ & & $25.37(0.36)$ & \\
\hline \multirow{5}{*}{ Age (years old) } & $60-65$ & $74.1(7.51)$ & & $25.77(5.23)$ & \\
\hline & $65-69$ & $75.83(7.92)$ & & $26.85(5.56)$ & \\
\hline & $70-74$ & $74.31(8.2)$ & $P<0.001$ & $24.93(5.58)$ & $P<0.001$ \\
\hline & $75-79$ & $72.38(8.17)$ & & $23.16(5.45)$ & \\
\hline & 80 and more & $73.22(7.32)$ & & $23.75(5.77)$ & \\
\hline \multirow{5}{*}{ Marital status } & Single & $73.69(7.82)$ & & $26.42(4.55)$ & \\
\hline & Married & $75.03(7.79)$ & & $26.24(5.15)$ & \\
\hline & Divorced & $72.48(7.98)$ & $P<0.001$ & $24.38(5.57)$ & $P<0.001$ \\
\hline & Dead wife & $71.26(7.94)$ & & $21.14(5.4)$ & \\
\hline & Male & $73.39(8.01)$ & & $25.76(5.6)$ & \\
\hline \multirow{4}{*}{ Education level } & Illiterate & $71.74(8.28)$ & & $21.87(5.47)$ & \\
\hline & Reading and writing & $73.95(7.91)$ & & $25.22(5.37)$ & \\
\hline & Diploma & $74.52(8)$ & $P<0.001$ & $2579(533)$ & $P<0001$ \\
\hline & Above diploma & $74.51(7.30)$ & & $26.75(5.42)$ & \\
\hline \multirow{3}{*}{ Ability to perform ADL } & Yes & $7.93(74.48)$ & & $25.71(5.27)$ & \\
\hline & No & $65.87(7.21)$ & $P<0.001$ & $18.75(5.98)$ & $P<0.001$ \\
\hline & Somewhat & $72.35(7.83)$ & & $22.59(5.84)$ & \\
\hline \multirow{5}{*}{ Employment status } & Employed & $73.34(7.23)$ & & $23.95(6.01)$ & \\
\hline & Housewife & $73.37(8.19)$ & & $25.07(5.87)$ & \\
\hline & & & $P=0.503$ & & $P=0.206$ \\
\hline & Retired & $73.97(8.15)$ & & $24.87(5.57)$ & \\
\hline & Out of work & $71.63(8.42)$ & & $23.26(4.61)$ & \\
\hline
\end{tabular}

Client-Centered Nursing Care

A study on general self-efficacy of elderly people in the senior home was carried out by Torki et al in Tehran in 2011.

The results of this study showed that the mean of selfefficacy was $21.44 \pm 3.83$, which was lower than the present study. However, another descriptive cross-sectional study with the aim of measuring self-efficacy and its associated factors was conducted among 87 elderly residents of a nursing home in 2014 (Naseh, Shaikhy \& Rafiei 2016). The data were collected using GSE-10. 
Table 3. Spiritual health of studied units-2015

\begin{tabular}{ccccc}
\hline Spiritual Health & MIN & MAX & Mean & SD \\
\hline Religious health (10-60) & 19 & 51 & 36.81 & 5.37 \\
Existential health (10-60) & 26 & 49 & 36.92 & 4.19 \\
Spiritual health (20-120) & 45 & 94 & 73.72 & 8.01 \\
\hline
\end{tabular}

Client-Centered Nursing Care

Table 4. The frequency distribution and numerical indexes of self-efficacy of the studied units

\begin{tabular}{ccc}
\hline Self-Efficacy & Frequency & Percent \\
\hline Low & 49 & 6 \\
\hline Medium & 376 & 45.7 \\
\hline High & 397 & 48.3 \\
\hline Total & 822 & 100 \\
\hline Mean (SD) & 24.71 (5.68) & $10-38$ \\
\hline Maximum-Minimum & &
\end{tabular}

The mean score of the general self-efficacy was $22.95 \pm$ 8.02 , indicating that most of the participants $(69 \%)$ had a low level of self-efficacy, which contradicted with the result of this study. This finding is feasible due to the deprivations in the nursing home.

General self-efficacy had a significant correlation with religious, existential, and spiritual health. This result is the same to Zareipour et al as recorded for unsanitary populations (Zareipour et al. 2016). Another study was carried out by Gonzales and Riox to identify factors affecting the spiritual health of the elderly people (Velasco-Gonzalez \& Rioux 2013). They concluded from their study that the relationship between selfefficacy as a part of the mental health of individuals is related to the spiritual health of elderly ones, which was similar to the results of this study. Konopack and McAuley (2012) conducted a study with the purpose of understanding Efficacy-mediated effects of spirituality and physical activity on quality of life. The result of the data analysis revealed that people with higher spirituality would have more self-efficacy and selfesteem, which indicated a link between spiritual health and self-efficacy. Also, their results of data analysis also showed that people with higher spirituality had more self-efficacy and self-care $(\mathrm{P}<0.01)$ (Konopack \& McAuley 2012).
Table 4 was used to achieve the third objective of "Determining the relationship between spiritual well-being and general self-efficacy in the elderly". In this regard, it can be concluded that the general self-efficacy is related to religious health, existential, and spiritual wellbeing statistically and the coefficients are determined to be $0.13,0.20$, and 0.19 , respectively. Another study in 2015 confirmed a significant relationship between physical, psychological and spiritual health with self-efficacy (Marzabadi 2015).

The results showed that general self-efficacy was related to the religious, existential, and spiritual health. Since old age is a major health challenge in the near future and shows the high prevalence of chronic and severe diseases and specific physical, mental, and social characteristics, so promoting spiritual health in elderly people can lead to self-efficacy.

\section{Acknowledgements}

This study is a part of the findings of the first author's MSc. thesis, which was done under the permission of Vice Chancellor's Office for Research of Iran University of Medical Sciences (IR.IUMS. REC.1394.9311580003). We are grateful to all of the 
elderly participants in this study and whoever helped us in conducting this study.

\section{Conflict of Interest}

The authors declared no conflicts of interest.

\section{References}

Adegbola, M., 2011. Spirituality, self-efficacy, and quality of life among adults with sickle cell disease. Southern Online Journal of Nursing Research, 11(1), p. 5. PMCID: PMC3137798

Asghari, F., et al., 2014. The relationship between academic selfefficacy and psychological well-being, family cohesion, and spiritual health among students of Kharazmi University. Iranian Journal of Medical Education, 14(7), pp. 581-93.

Bai, M. \& Dixon, J. K., 2014. Exploratory factor analysis of the 12item functional assessment of chronic illness therapy-spiritual well-being scale in people newly diagnosed with advanced cancer. Journal of Nursing Measurement, 22(3), pp. 404-20. doi: 10.1891/1061-3749.22.3.404

Bai, M. \& Lazenby, M., 2015. A Systematic review of associations between spiritual well-being and quality of life at the scale and factor levels in studies among patients with cancer. Journal of Palliative Medicine, 18(3), pp. 286-98. doi: 10.1089/ jpm.2014.0189.

Bakhtiyari, F., et al., 2014. Validation of the persian version of Abbreviated Mental Test (AMT) in elderly residents of Kahrizak charity foundation. Iranian Journal of Diabetes and Metabolism, 13(6), pp. 487-94

Bekhet, A. K. \& Zauszniewski, J. A., 2012. Mental health of elders in retirement communities: Is loneliness a key factor? Archives of Psychiatric Nursing, 26(3), pp. 214-24. doi: 10.1016/j. apnu.2011.09.007.

French, D. P., et al., 2014. Which behaviour change techniques are most effective at increasing older adults' self-efficacy and physical activity behaviour? A systematic review. Annals of Behavioral Medicine, 48(2), pp. 225-34. doi: 10.1007/s12160-0149593-z.

Griffin, J. E., 2012. Correlations of spirituality and self-efficacy for weight loss behaviors among African American women (PhD dissertation). Ohio: Ohio State University.

Hosseini, H., Torkani, S. \& Tavakol, K., 2013. The effect of community health nurse home visit on self-care self-efficacy of the elderly living in selected Falavarjan villages in Iran in 2010. Iranian Journal of Nursing and Midwifery Research, 18(1), pp. 4753. PMCID: PMC 3748555

Konopack, J. F. \& McAuley, E., 2012. Efficacy-mediated effects of spirituality and physical activity on quality of life: A path analysis. Health and Quality of Life Outcomes, 10(1), p. 57. doi: 10.1186/1477-7525-10-57.
Lavretsky, H., 2010. Spirituality and aging. Aging Health, 6(6), pp. 749-69. doi: $10.2217 /$ ahe.10.70.

Marzabadi, A., 2015. Relationship between physical-mental health and spirituality with self-efficacy in military staff. Journal of Military Medicine, 16(4), pp. 217-23.

Naseh, L., Shaikhy, R. \& Rafiei, H., 2016. General self-efficacy and associated factors among elderly residents of nursing home. Journal of Holistic Nursing And Midwifery, 26(2), pp. 90-7.

Rahimi, A., et al., 2013. Exploring spirituality in Iranian healthy elderly people: A qualitative content analysis. Iranian Journal of Nursing and Midwifery Research, 18(2), pp. 163-70. PMCID: PMC3748574

Takeda, K., et al., 2009. Relationships between spirituality, health self-efficacy and health locus of control in the elderly. Kawasaki Journal of Medical Welfare, 14(2), pp. 81-91.

Torki, Y., et al., 2011. General self efficacy in elderly living in resthomes. Iran Journal of Nursing, 24(73), pp. 55-62.

Velasco-Gonzalez, L. \& Rioux, L., 2013. The spiritual well-being of elderly people: A study of a fench sample. Journal of Religion and Health, 53(4), pp. 1123-37. doi: 10.1007/s10943-013-9710-5.

Victor, C. R., Burholt, V. \& Martin, W., 2012. Loneliness and ethnic minority elders in great Britain: An exploratory study. Journal of Cross-Cultural Gerontology, 27(1), pp. 65-78. doi 10.1007/s10823-012-9161-6.

World Health Organization., 2013. Aging and health. Geneva: World Health Organization.

Zareipour, M., et al., 2016. The association between spiritual health and blood sugar control in elderly patients with type 2 diabetes. Elderly Health Journal, 2(2), pp. 67-72. 
May 2017 . Volume 3. Number 2

Client-Centered Nursing Care 